\title{
Enhance the biocompatibility and osseointegration of polyethylene terephthalate ligament by plasma spraying with hydroxyapatite in vitro and in vivo
}

This article was published in the following Dove Press journal: International Journal of Nanomedicine

\author{
Siheng Wangl,* \\ Yunshen $\mathrm{Ge}^{1, *}$ \\ Chengchong $\mathrm{Ai}^{\prime}$ \\ Jia Jiang' \\ Jiangyu Cai' \\ Dandan Sheng' \\ Fang Wan' \\ Xingwang Liu' \\ Yuefeng $\mathrm{HaO}^{2}$ \\ Jun Chen' \\ Shiyi Chen' \\ 'Department of Sports Medicine \\ and Arthroscopy Surgery, Huashan \\ Hospital, Shanghai, People's Republic \\ of China; ${ }^{2}$ Sports Medicine Center, \\ Affiliated Suzhou Hospital of Nanjing \\ Medical University, Suzhou Municipal \\ Hospital, Suzhou, Jiangsu, People's \\ Republic of China \\ *These authors contributed equally \\ to this work
}

Correspondence: Yuefeng Hao Sports Medicine Center, Affiliated Suzhou Hospital of Nanjing Medical University,

Suzhou Municipal Hospital,

No 242, Guangii Rd., Gusu District,

Suzhou 215008, Jiangsu,

People's Republic of China

Email 13913109339@163.com

Shiyi Chen

Department of Sports Medicine and Arthroscopy Surgery, Huashan Hospital, No 12, Middle Urumqi Road, Jing'an

District, Shanghai 200040,

People's Republic of China

Tel +86 2l 52888255

Fax +86 2I 62496020

Email cshiyi@I63.com
Purpose: This study was designed to evaluate the biocompatibility and osseointegration of polyethylene terephthalate ligament after coating with hydroxyapatite (PET/HA) by using the plasma spraying technique in vitro and in vivo.

Methods: In this study, PET/HA sheets were prepared by using the plasma spraying technique. The characterization, the viability of bone marrow stromal cells (BMSCs), and the mRNA expression of bone formation-related genes were evaluated in vitro. The osseointegration in vivo was investigated in the rabbit anterior cruciate ligament (ACL) reconstruction model by microcomputed tomography (micro-CT) analysis, histological evaluation, and biomechanical tests. Results: Scanning electron microscopy (SEM) results showed that the surface of polyethylene terephthalate (PET) becomes rough after spraying with hydroxyapatite (HA) nanoparticles, and the water contact angle was $75.4^{\circ} \pm 10.4^{\circ}$ in the PET/HA-plasma group compared to $105.3^{\circ} \pm 10.9^{\circ}$ in the control group $(p<0.05)$. The cell counting kit- 8 counting results showed that the number of BMSCs significantly increased in the PET/HA-plasma group $(p<0.05)$. Reverse transcription polymerase chain reaction (RT-PCR) results showed that there was an upregulated mRNA expression of bone formation-related genes in the PET/HA-plasma group $(p<0.05)$. Micro-CT results showed that the transactional area of tibial tunnels and femoral tunnels was smaller in the PET/HA-plasma group $(p<0.05)$. The histological evaluation scores of the PET/HA-plasma group were significantly superior to those of the PET control group at 8 and 12 weeks $(p<0.05)$. The biomechanical tests showed an increased maximum load to failure and stiffness in the PET/ HA-plasma group compared to those in the control group at 8 and 12 weeks.

Conclusion: Both in vitro and in vivo results demonstrated in this study suggest that the biocompatibility and osseointegration of PET/HA ligament were significantly improved by increasing the proliferation of cells and upregulating the expression of bone formation-related genes. In a word, the PET/HA-plasma ligament is a promising candidate for ACL reconstruction in future.

Keywords: sprayed mineralization, HA, graft-to-bone healing, ligament reconstruction, rabbit model

\section{Introduction}

The incidence of anterior cruciate ligament (ACL) injuries has increased in the past few decades. In the US, the incidence has risen from 32.9/100,000 person-years in 1994 to $43.5 / 100,000$ person-years at present, ${ }^{1}$ and surgical reconstruction is essential in athletes who require early return to antagonistic sports. ${ }^{2}$ Autografts, allografts, and artificial ligaments are the three options for ligament reconstruction, among which artificial ligament has been accepted as a choice for clinical reconstruction 
of ligaments. Because of its solid mechanical property and less donor-site side effects, artificial ligament can promise a fast recovery compared to autografts and allografts. ${ }^{2-4}$ However, the Ligament Augmentation and Reconstruction System (LARS) made of polyethylene terephthalate (PET) material was poor in osteoconductivity, which has limited its application in ACL reconstruction. Several cases of ACL reconstruction have reported that lack of osseointegration in grafts was related to long-term failure. ${ }^{5}$

Synthetic materials for ACL reconstruction and modification of those materials have been investigated for their potential to address the challenges of osseointegration. ${ }^{6-9}$ Our previous studies have applied gelatin, ${ }^{10}$ silk fibroin, ${ }^{11}$ and material based on calcium phosphate ${ }^{12}$ to artificial ligament using different surface modification techniques, which have shown positive effect on the biological performance. Among these materials, HA has been proved to improve osseointegration after applied on PET ligament. ${ }^{12} \mathrm{HA}$, which is the natural component of bone tissue, has been studied in a series of researches for implant surface modification. ${ }^{13-15}$ Multiple studies have investigated the biological performance and the material characteristics of HA-based surface modification. ${ }^{16-18}$ Strąkowska et al ${ }^{17}$ modified hydroxyapatite on Ti6Al4V substrates by electrochemically assisted deposition, and improvement in cell proliferation was observed. Koirala et al $^{18}$ synthesized biomimetic hydroxyapatite nanoconstruct (nanosized hydroxyapatite [NHAp]) using a double emulsion technique combined with a chemical gradient across a lipid bilayer for surface modification of a titanium (Ti) implant. The result indicated that the surface modification provides an environment essential for cell adhesion. However, these techniques for surface modification were not sufficient to form a reliable adhesion between HA and substrates. Furthermore, these chemical synthesis modification techniques that involved chemical solvents have potential to biotoxicity, which has limited their further clinical application.

In order to acquire a more reliable coating of HA on the surface of PET and to minimize the potential toxicity caused by chemical residue of biochemical reagents, the plasma spraying technique was introduced in this study. Materials modified using the plasma spraying technique have been investigated by several studies ${ }^{19,20}$ and have been proved to improve cell proliferation on these materials. In this technique, HA nanoparticles were carried by heated plasma beam and precipitated onto substrates. ${ }^{19}$ In previous studies ${ }^{19,20}$ the surface temperature in the coating process was $450^{\circ} \mathrm{C}-600^{\circ} \mathrm{C}$, which was higher than the phase change point of PET. ${ }^{6}$ The application of the plasma spraying technique in polymer modification was limited because of the high temperature in the coating process. ${ }^{21}$ To the best of our knowledge, it has not been studied yet to apply the plasma spraying technique to modify PET artificial ligaments. Recent progress $^{21}$ in the plasma spraying technique has lowered its reaction temperature, which has made it possible to apply the plasma spraying technique in polymer surface modification. Vogel et $\mathrm{al}^{21}$ coated poly-ether-ether-ketone (PEEK) with rough and porous titanium plasma spray (TPS) coatings, and the results proved that the materials were able to meet the required mechanical strength after plasma spraying.

Our hypothesis was that PET ligament plasma sprayed with HA can promote bone-to-graft healing effect by enhancing the bone formation-related genes. In addition, we assessed the characteristics and biological performance in vitro and in vivo.

\section{Methods}

\section{Preparation of PET/HA-plasma and PET/HA-immersed}

The PET sheets were cut from a LARS ligament (Surgical Implants and Devices, Arc-sur-Tille, France). The average thickness of the sheet was $0.45 \pm 0.05 \mathrm{~mm}$. The PET sheets were treated with plasma surface modification (HPD-100B Plasma Apparatus; Coronalab Co., Ltd., Nanjing, China) at $50 \mathrm{~V}, 2 \mathrm{~mA}$ for 3 minutes. After that, the sheets were cleaned with $100 \%(\mathrm{v} / \mathrm{v})$ acetone and $75 \%(\mathrm{v} / \mathrm{v})$ ethanol in sequence, and then dried in room temperature for 24 hours. For the PET/ HA-plasma group, HA coatings were performed with an arc current of $550 \mathrm{~A}$ and a voltage of $30 \mathrm{~V}$ (Metco-9MB thermal spray gun; Sanxin Metal S\&T Co., Ltd., Guangzhou, China). For the PET/HA-immersed group, the coating was conducted in accordance to a previous study. ${ }^{22}$ Briefly, a solution of $250 \mathrm{mmol} / \mathrm{L} \mathrm{CaCl}_{2}-250 \mathrm{mmol} / \mathrm{L} \mathrm{KH}_{2} \mathrm{PO}_{4}$ was prepared, and its $\mathrm{pH}$ was adjusted to 8.9 using a $\mathrm{NaOH}$ solution. The final products were acquired by immersing PET sheets in the solution at $25^{\circ} \mathrm{C}$ for 24 hours.

\section{Characterization}

The characterization of PET/HA sheets was studied by scanning electron microscopy (SEM) at $20 \mathrm{kV}$ (GeminiSEM, Zeiss, Germany). Processing of SEM images was performed using ImageJ software (National Institutes of Health, Bethesda, MD, USA). The average number of nanoparticles and the distribution of diameter were evaluated. ${ }^{23}$ Chemical elemental analysis of HA coated on the surface of PET sheet was detected by 
energy-dispersive spectrometer (EDS; GeminiSEM). Surface hydrophilicity of samples was detected by water contact angle (JC200C1; Zhongchen Co., Shanghai, China).

\section{In vitro biocompatibility study}

All steps were approved by the Animal Research Committee of Shanghai Jiaotong University Animal Science Department. Bone marrow stromal cells (BMSCs) were obtained according to previously described protocols ${ }^{24}$ from the femur of 4-week-old New Zealand rabbit. The cells were cultured in medium $(10 \%[\mathrm{v} / \mathrm{v}]$ fetal bovine serum $[\mathrm{FBS}]+\mathrm{DMEM})$ at $37^{\circ} \mathrm{C}, 5 \% \mathrm{CO}_{2}$. The $\mathrm{P} 2$ generation of the cells was resuspended to a cell density of $1 \times 10^{5} / \mathrm{mL}$ for further experiments. The PET sheets were cut to the size of $0.5 \times 0.5 \mathrm{~cm}$ and then cleaned with $75 \%(\mathrm{v} / \mathrm{v})$ ethanol for 1 hour. The resuspended P2 cells were seeded onto the cleaned PET sheets.

The viability of BMSCs was evaluated by cell counting kit-8 (CCK-8) at 1, 3, 7, and 14 days (Dojindo Co., Ltd., Shanghai, China). The absorbance was measured at $450 \mathrm{~nm}$ with a microplate reader (Multiskan FC; Thermo Fisher Scientific, Waltham, MA, USA). The mRNA expression of the genes that related to the new bone formation process, including $B M P-2, O C N$, eNOS, and $V E G F$, was determined by real-time polymerase chain reaction (PCR) assay. The PET/BMSC sheets were added with $1 \mathrm{~mL}$ DMEM+FBS medium and cultured for $1,3,7$, and 14 days. Total RNA was extracted from the cell lysis with chloroform (analytically pure), isopropyl (analytically pure), and 75\% (v/v) ethanol in sequence. The absorbance of the extraction at 260 and $280 \mathrm{~nm}$ was evaluated using ultraviolet spectrophotometer (He $\lambda$ ios; Thermo Fisher Scientific) to evaluate the concentration of the extraction. Agarose gel electrophoresis (AGE) was performed to determine the quality of RNA. The RNA was then reverse transcripted to cDNA using reverse transcriptase Moloney Murine leukemia virus (Takara D2640A; Thermo Fisher Scientific). The primer design is shown in Table 1. The $2^{\Delta \Delta C_{\mathrm{t}}}$ method was used to evaluate fold changes in mRNA expression levels. Geometric means of the reference genes were utilized to normalize the expression under different experimental conditions. GAPDH was used as a reference gene.

\section{Animal test}

Animal experimental procedures were approved by the Animal Research Committee of Shanghai Jiaotong University Animal Science Department. All procedures were performed following the Guide for the Care and Use of Laboratory Animals of the National Institutes of Health and the Animal Welfare Act. A total of 72 New Zealand rabbits with a weight of $2.9 \pm 0.2 \mathrm{~kg}$ were included and randomized to the PET/HA-plasma group $(n=24)$, PET/HA-immersed group ( $n=24)$, and control group $(n=24)$. The PET/HA sheets were then cut into a size of $0.6 \times 100 \mathrm{~mm}$ and rolled up into ligament. The diameter of the ligament was $2.0 \mathrm{~mm}$. Acute ACL reconstruction model was built according to previous works. ${ }^{25}$ As shown in Figure 1, an incision medial to patella was established, and the patella was dislocated laterally. The ACL was then visualized and sharply dissected. A tibial tunnel with a diameter of $2 \mathrm{~mm}$ was drilled from the ACL insertion on tibial plateau to the medial/proximal tibia using a Kirschner wire. A femoral tunnel was similarly prepared from the ACL femoral insertion to the distal femur using a Kirschner wire. The ligaments were introduced through the bone tunnels using passing sutures and were then fixed to periosteum using sutures. A posterior drawer test was performed when fixing the ligament to ensure the tension of the ligament. Knee joints of the rabbits were sacrificed 4, 8, and 12 weeks post surgery for further study.

\section{Imaging evaluation}

The animals were sacrificed as planned after surgery, and the femoral-graft-tibia complex samples $(n=6)$ were fixed

Table I Primers for bone formation genes

\begin{tabular}{|c|c|c|c|}
\hline Gene & Primer sequence $\left(5^{\prime}-3^{\prime}\right)$ & $\begin{array}{l}\text { Annealing } \\
\text { temperature }\left({ }^{\circ} \mathrm{C}\right)\end{array}$ & $\begin{array}{l}\text { Fragment } \\
\text { length (bp) }\end{array}$ \\
\hline \multirow[t]{2}{*}{ GAPDH (NM_00I082253.I) } & Forward primer: GGCCGCCCAGAACATCATCC & 58 & 152 \\
\hline & Reverse primer: СTTTCTCCAGGCGGCAGGTCAGGT & & \\
\hline \multirow[t]{2}{*}{ BMP-2 (NM_00I082650.I) } & Forward primer: AAAGCGTCAAGCGAAACACAAACA & 56 & 113 \\
\hline & Reverse primer: GAGGGGCCACAATCCAGTCGT & & \\
\hline \multirow[t]{2}{*}{ OCN (XM_0027I5383.3) } & Forward primer: AGGGCCCTCACTCTTGTCG & 58 & 149 \\
\hline & Reverse primer: CGCCGGGCTCGCTTCAC & & \\
\hline \multirow[t]{2}{*}{ eNOS (NM_001082733.I) } & Forward primer: CCGCGGCCAGAGCAGCACAAGAGT & 60 & 200 \\
\hline & Reverse primer: ACCGCACGAGCAAAGGCACAGAAG & & \\
\hline \multirow[t]{2}{*}{ VEGF (AYI96796.I) } & Forward primer: ATGGCAGAAGAAGGAGACAATAAA & 58 & 170 \\
\hline & Reverse primer: CCCCCACAGCGCACCAGAG & & \\
\hline
\end{tabular}


A

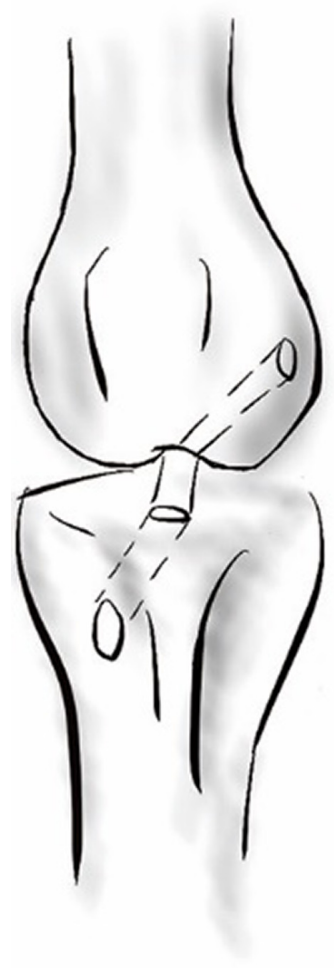

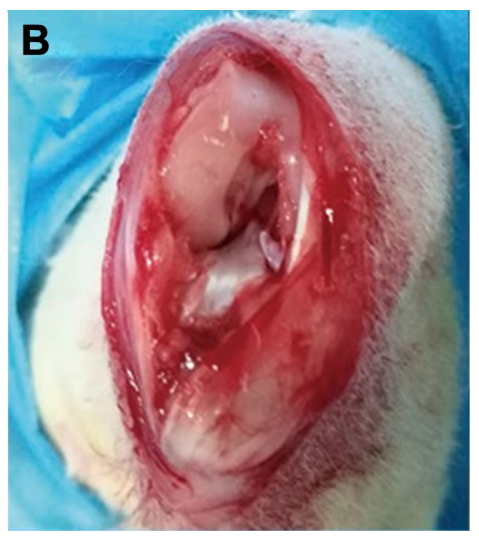
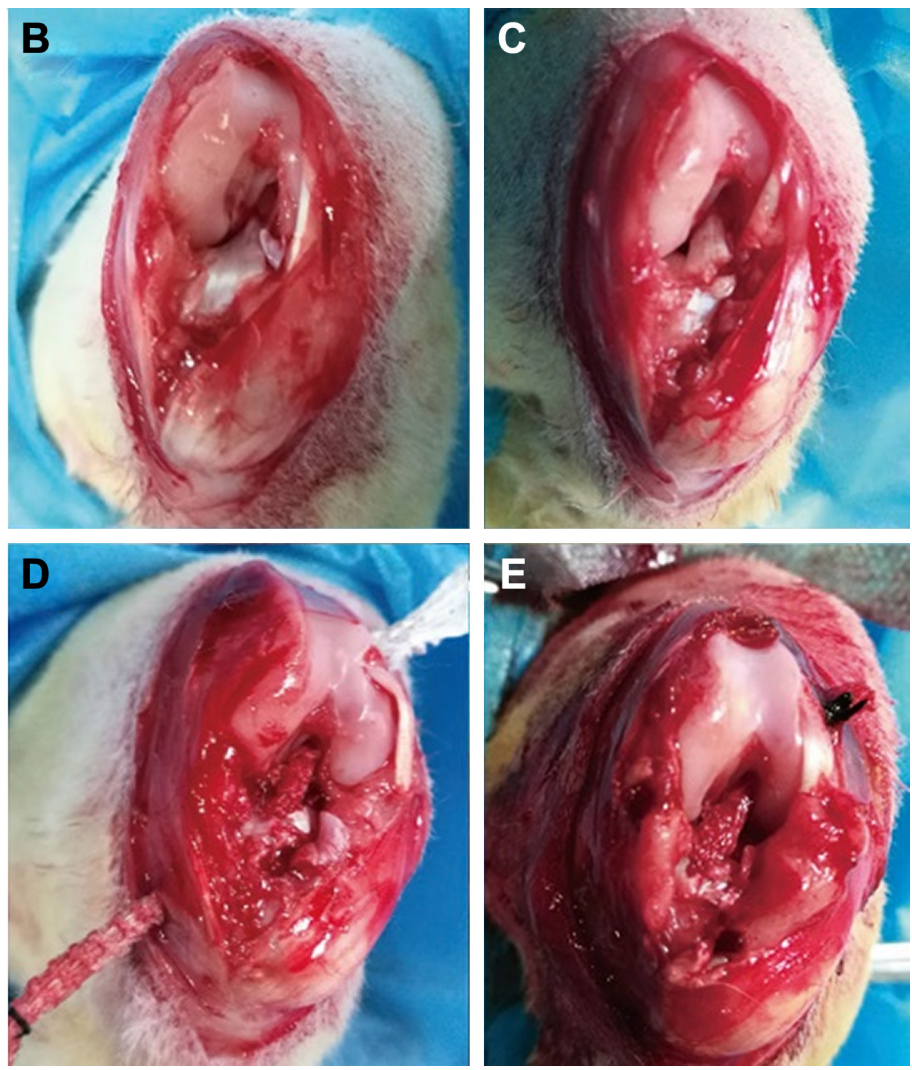

Figure I Scheme of the procedure for $\mathrm{ACL}$ reconstruction using artificial ligament.

Notes: (A) Schematic graph of reconstructed ACL using artificial ligament. (B) Excision of the articular capsule and exposure of the ACL. (C) Splitting of ACL. (D) Graft passing through the bone tunnel. (E) Fixation of the graft to periosteum using nonabsorbable suture.

Abbreviation: $\mathrm{ACL}$, anterior cruciate ligament.

in $10 \%$ formalin for 24 hours and collected for micro-CT analysis. All the images were acquired using a micro-CT scanner (Skyscan 1176; Bruker Optik GmbH, Ettlingen, Germany). The acquisition parameters were as follows: voltage $=65 \mathrm{kV}$, current $=380 \mu \mathrm{A}$, exposure time $=385 \mathrm{~ms}$, and camera binning $=2 \times 2$. Images were reconstructed and analyzed by the scanner software CTV ox 3.3 and DataViewer 1.5.2.4 (Bruker Co. Ltd.). Transactional bone tunnel area (per square millimeter) was detected and analyzed (Figure 2A).

\section{Histology analysis}

After micro-CT scan, the femoral-graft-tibia samples were cut into sheets with a thickness of 4-6 mm and decalcified in $10 \%$ ethylenediamine tetra acetic acid for 6 weeks. Then, the samples were sectioned perpendicular to the longitudinal axis of the grafts in the middle portion of the bone tunnel. The sections were then stained with hematoxylin-eosin (H\&E) and Masson trichrome and photographed using routine light microscopy (CX41; Olympus Corporation, Tokyo, Japan). Morphological analysis was performed using ImageJ software. Five sections were chosen for each femoral-graft-tibia sample, and each section was divided into four quadrants for further measurement. In each of the four quadrants, the slices were measured four times. Then, the digital photographs were graded according to the modified graft-to-bone histologic score (Table 2). ${ }^{26,27}$ The two investigators who performed the morphological analysis were blinded to the design of animal treatment.

\section{Biomechanical tests}

Immediately after sacrifice, the femoral-graft-tibia samples $(n=6)$ were harvested from each knee and prepared for mechanical testing. Mechanical test was conducted using a material testing system machine (WDW-30C; Hualong Co., Shanghai, China). The femoral and tibial bone samples were fixed firmly in clamps. The long axis of tibial bone and femoral bone was oriented parallel to the testing axis (Figure 3A). Prior to conducting the tensile test, the specimen was preloaded with a preload of $1 \mathrm{~N}$ for 5 minutes. Immediately after preconditioning, the ultimate pullout load was investigated using an elongation rate of $2 \mathrm{~mm} / \mathrm{min}$. For each specimen, the testing was completed when the graft ruptured or was pulled out of the bone tunnel. The maximal pullout load $(\mathrm{N})$ and stiffness $(\mathrm{N} / \mathrm{mm})$ were recorded. 

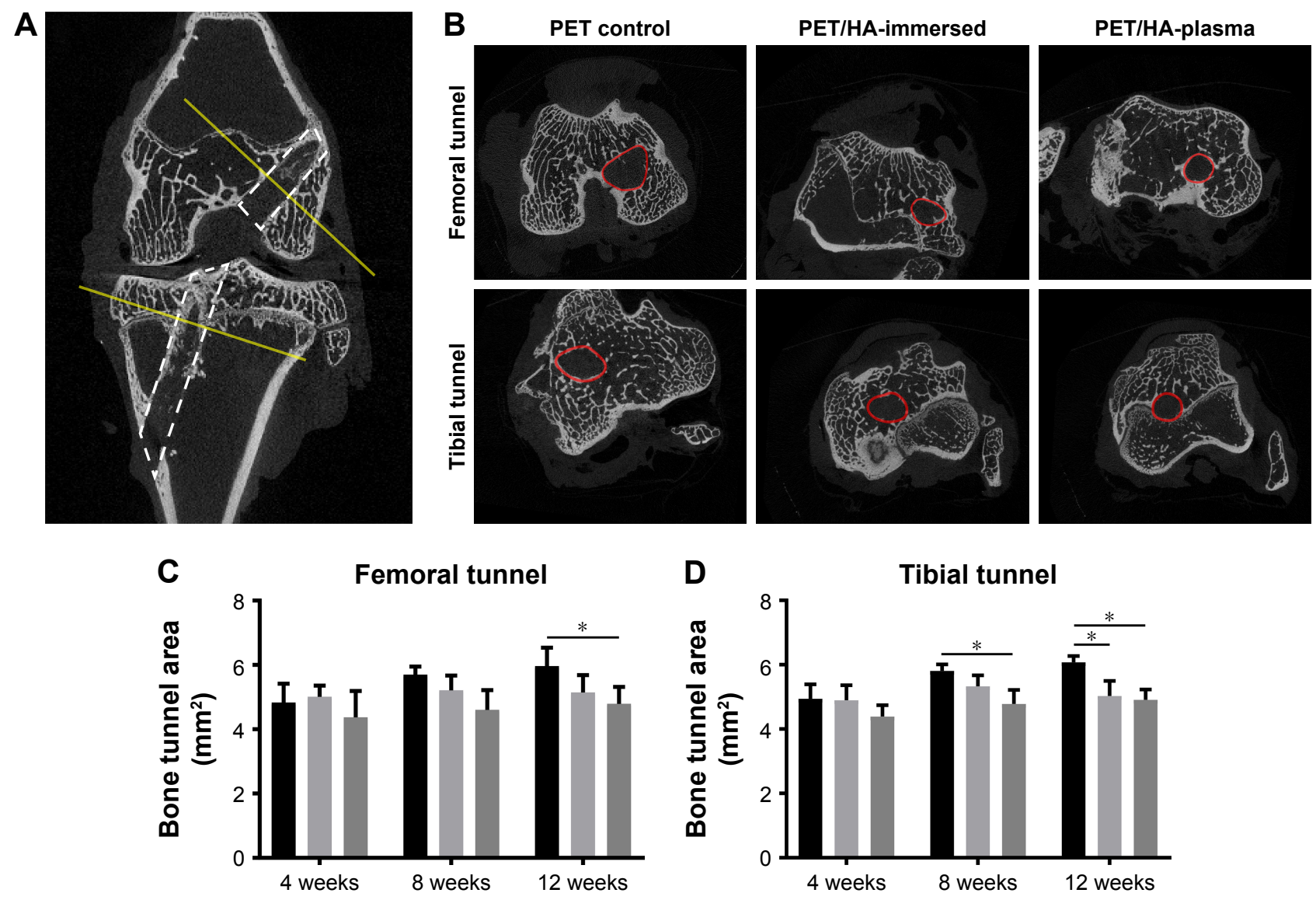

PET control $\square$ PET/HA-immersed $\square$ PET/HA-plasma

Figure 2 Micro-CT analysis of tibial and femoral bone tunnel size.

Notes: (A) Coronary view of femoral and tibial bone tunnel after ACL reconstruction showing the plane selected for bone tunnel area analysis. (B) Transactional sections of femoral and tibial bone tunnels in the PET/HA-plasma group, PET/HA-immersed group, and PET control group. Average (C) femoral and (D) tibial bone tunnel area in the PET/HA-plasma group, PET/HA-immersed group, and PET control group at 4, 8, and I2 weeks postoperatively. ${ }^{*} p<0.05$.

Abbreviations: micro-CT, micro-computed tomography; $\mathrm{ACL}$, anterior cruciate ligament; $\mathrm{PET}$, polyethylene terephthalate; HA, hydroxyapatite.

\section{Statistics}

The mean and standard deviation were used to describe the data, and the data analysis was performed using the Stata 10.0 software (StataCorp LP, College Station, TX, USA). The statistical analysis of the quantitative results was carried out

Table 2 The modified graft-to-bone histologic score

\begin{tabular}{lllll}
\hline Scoring criteria & \multicolumn{4}{l}{ Tendon histologic score } \\
\cline { 2 - 5 } & $\mathbf{I}$ & $\mathbf{2}$ & $\mathbf{3}$ & $\mathbf{4}$ \\
\hline IF width & Not & Wide & Medium & Narrow \\
& generated & & & \\
Tissue/total area, \% & 5 & $5-10$ & $10-20$ & 20 \\
Cellularity & Marked & Moderate & Mild & Minimal \\
Rounding of nuclei & Severely & Moderately & Slightly & Long spindle \\
& rounded & rounded & rounded & shape \\
Inflammation & 30 & $20-30$ & $10-20$ & 10 \\
(area infiltrated by & & & & \\
inflammatory cells), \% & & & & \\
\hline
\end{tabular}

Abbreviation: IF, interface. using a one-way analysis of variance (ANOVA) test between two groups and a two-way ANOVA test among three groups. The statistical significance level was set to 0.05 .

\section{Results \\ Characterization}

Figure 4A-C depicts the photographs of PET and PET/HA sheets, which showed no significant change in shape and color after HA coating. SEM graphs revealed that the surface of fiber in the PET control group was smooth, while the surface of fiber in the PET/HA-plasma group and PET/HA-immersed group was rough, which indicated that the fibers in these two groups were coated with HA nanoparticles. In the PET/HAimmersed group, the HA nanoparticles were flake shaped, while in the PET/HA-plasma group, the nanoparticles were sphere shaped (Figure 4D-F). Figure 4G shows that the number of the nanoparticles was less in the PET/HA-immersed group $\left(1,231 \pm 94 / \mathrm{mm}^{2}\right)$ than that in the PET/HA-plasma 

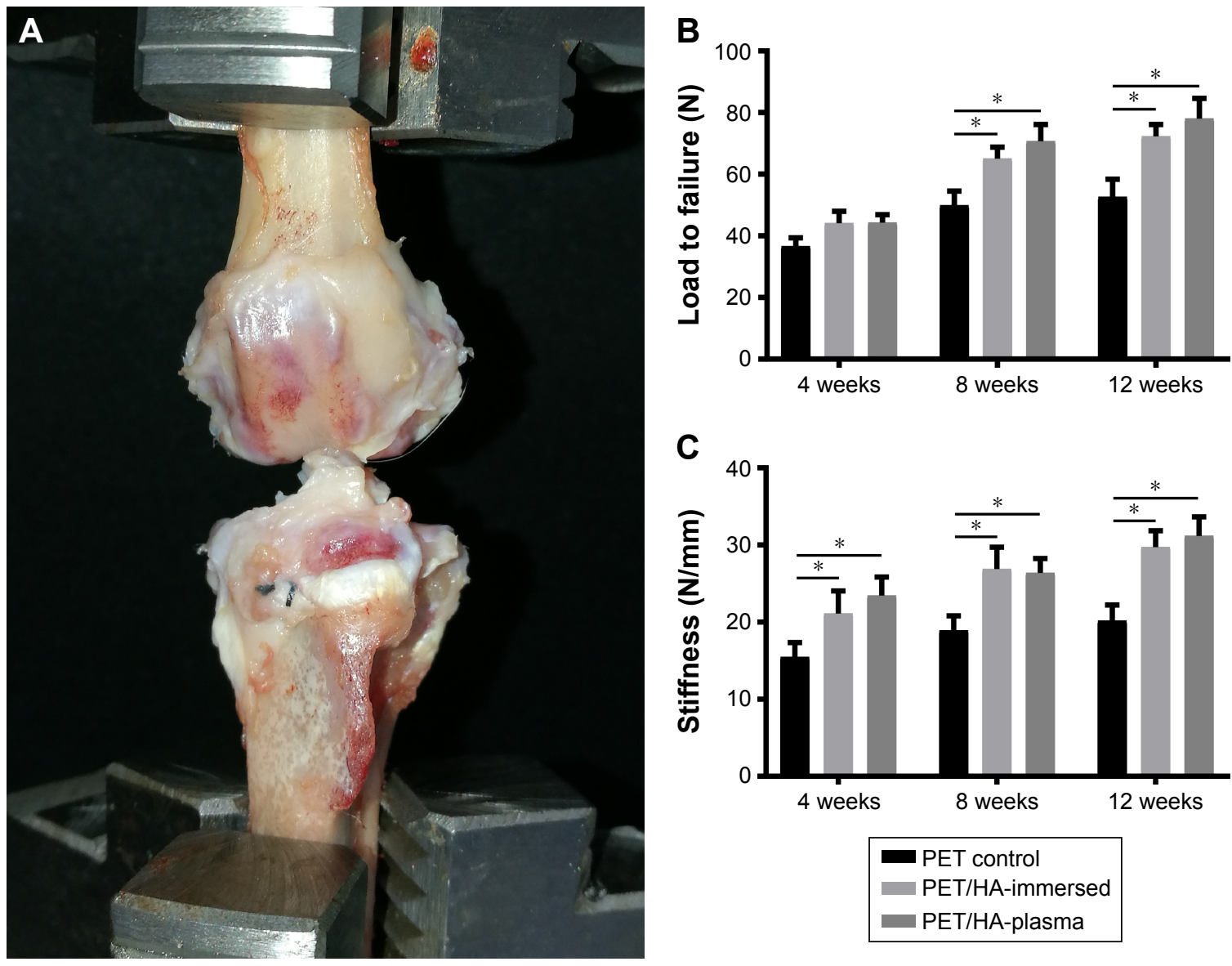

Figure 3 Biomechanical tests of the harvest samples.

Notes: (A) Harvested sample experiencing biomechanical tests. (B) Statistical analysis of ultimate load to failure of the samples at different times. (C) Statistical analysis of stiffness of the samples at different times. $* p<0.01$.

Abbreviations: PET, polyethylene terephthalate; HA, hydroxyapatite.

group $\left(1,662 \pm 149 / \mathrm{mm}^{2}\right)$. Figure $4 \mathrm{H}$ shows that the HA nanoparticles in the PET/HA-plasma group had a narrow diameter distribution width, which indicated that the size of HA nanoparticles was on the same order of magnitude.

Chemical elemental distribution of our products was analyzed by EDS. Figure 5 illustrates the mapping of the $\mathrm{Ca}$ and $\mathrm{P}$ elemental distribution; a higher density of signals in the PET/HA-plasma group was observed. This result suggested that HA was more effectively coated on PET in the PET/HA-plasma group. The $\mathrm{Ca} / \mathrm{P}$ ratio was $1.6 / 1$, which was in coordinance with the $\mathrm{Ca} / \mathrm{P}$ ratio in $\mathrm{HA}$.

The hydrophilicity of HA/PET was analyzed by water contact angle measurement. Figure 6 shows that the contact angle of the PET/HA-immersed group $\left(87.6^{\circ} \pm 10.0^{\circ}\right)$ and the PET/HA-plasma group $\left(75.4^{\circ} \pm 10.4^{\circ}\right)$ was significantly smaller than that of the PET control group $\left(105.3^{\circ} \pm 10.9^{\circ}\right.$, $p<0.05)$, which means that the hydrophobicity decreased in the PET/HA-plasma and PET/HA-immersed groups compared to the control group.

\section{In vitro cytocompatibility}

The level of BMSC proliferation was determined by CCK-8 cell counting. As shown in Figure 7A, the cell number in the PET/HA-plasma, PET/HA-immersed, and PET control groups showed no significant difference at 1 and 3 days. However, the cell viability was significantly higher in the PET/HA-plasma group compared to that in the PET/HAimmersed group $(p<0.05)$ and the PET control group $(p<0.05)$ at 7 and 14 days. In addition, the cell number in the PET/HA-immersed group was also higher than that in the PET control group at 14 days $(p<0.05)$.

The expression of bone formation-related genes, including BMP-2, OCN, eNOS, and VEGF, was detected by reverse transcription polymerase chain reaction (RT-PCR). As shown in Figure 7B, the BMP-2 expression was significantly upregulated in the PET/HA-plasma group compared to that in the PET control group at 3, 7, and 14 days $(p<0.05)$. In addition, the BMP-2 expression level was significantly higher in the PET/HA-plasma group compared to that in the 

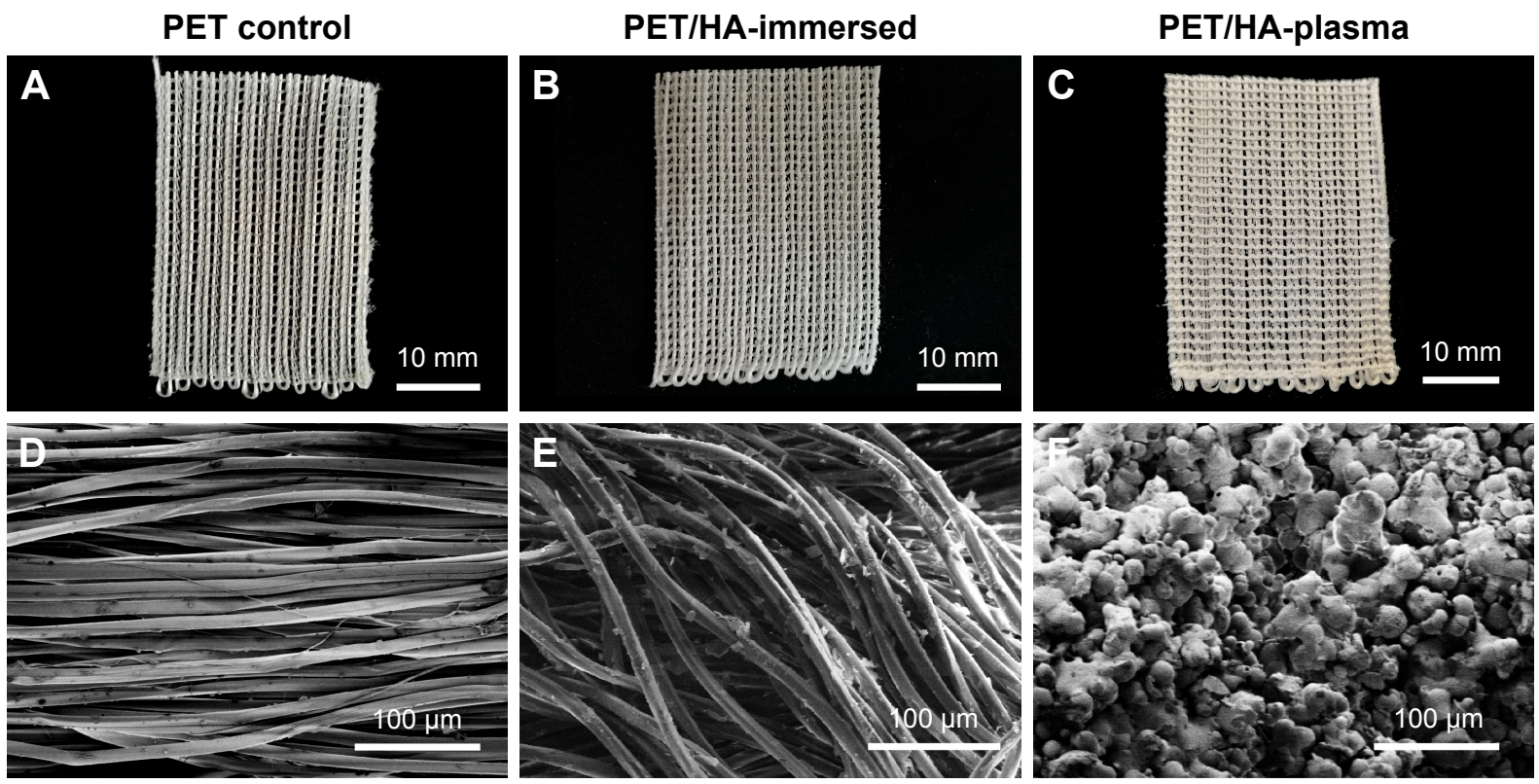

G

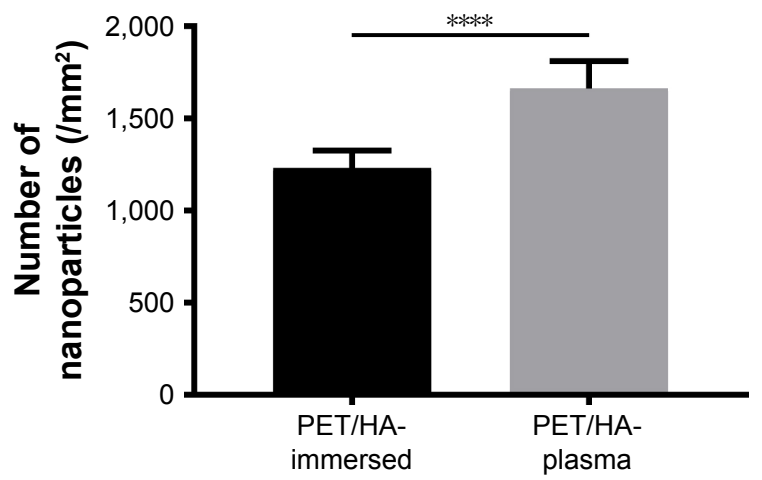

H

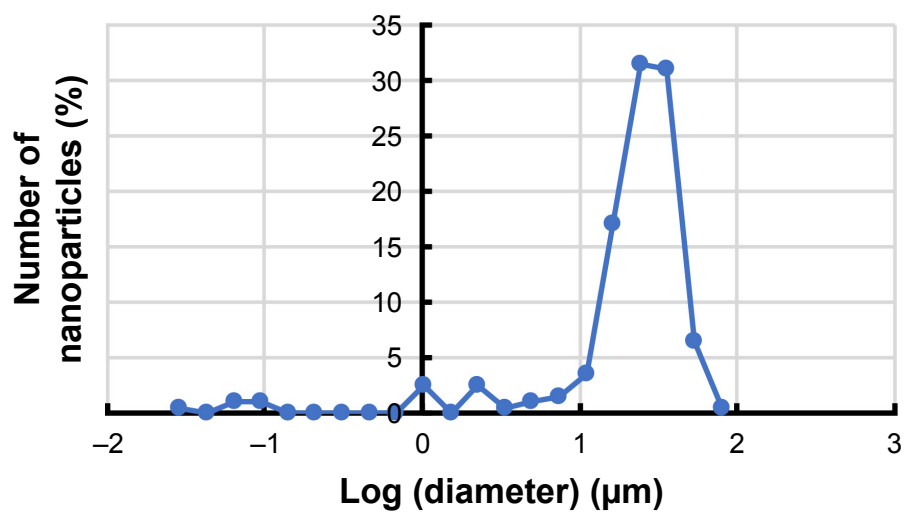

Figure 4 Characteristics of HA mineralized on PET.

Notes: Surface-modified material sheets in the (A) PET control, (B) PET/HA-immersed, and (C) PET/HA-plasma groups, bar=I0 mm. SEM image of the coating characteristics showing the distribution of nanoparticles in the (D) PET control, (E) PET/HA-immersed, and (F) PET/HA-plasma groups, bar=I00 $\mu \mathrm{m}$. (G) Average number of nanoparticles $\left(/ \mathrm{mm}^{2}\right)$ in the chemical-deposited and plasma-sprayed groups. $(\mathbf{H})$ Diameter distribution of the nanoparticles in the PET/HA-plasma group. **** $p<0.000 \mathrm{I}$.

Abbreviations: HA, hydroxyapatite; PET, polyethylene terephthalate; SEM, scanning electron microscopy.

PET/HA immersed group at 7 and 14 days $(p<0.05)$. As shown in Figure $7 \mathrm{C}$, the OCN expression was significantly upregulated in the PET/HA-plasma and PET/HA-immersed groups compared to that in the PET control group at 3, 7, and 14 days $(p<0.05)$. As shown in Figure 7D, the eNOS expression was significantly upregulated in the PET/HA-plasma group compared to that in the PET control group at 3, 7, and 14 days $(p<0.05)$. No significant difference in the eNOS expression level was observed between the PET/HA-plasma and PET/HA-immersed groups. As shown in Figure 7E, the VEGF expression was significantly upregulated in the PET/ HA-plasma group compared to that in the PET control group at 3,7 , and 14 days $(p<0.05)$. In addition, the VEGF expression level was significantly higher in the PET/HA-plasma group compared to that in the PET/HA immersed group at 7 and 14 days $(p<0.05)$. These results demonstrated that the mRNA expression related to the bone formation process was upregulated in the PET/HA-plasma group than in the PET/ HA-immersed and PET control groups.

\section{Micro-CT analysis of bone tunnel}

The in vivo experiment results were further analyzed by micro-CT, histology, and biomechanical tests. The transactional area of femoral and tibial bone tunnel was measured by micro-CT at 4,8 , and 12 weeks to evaluate the preventive effect of HA plasma spraying modification on bone tunnel resorption (Figure 2B). The mean area of femoral tunnel is shown in Figure 2C. The area of femoral tunnel at 4 and 

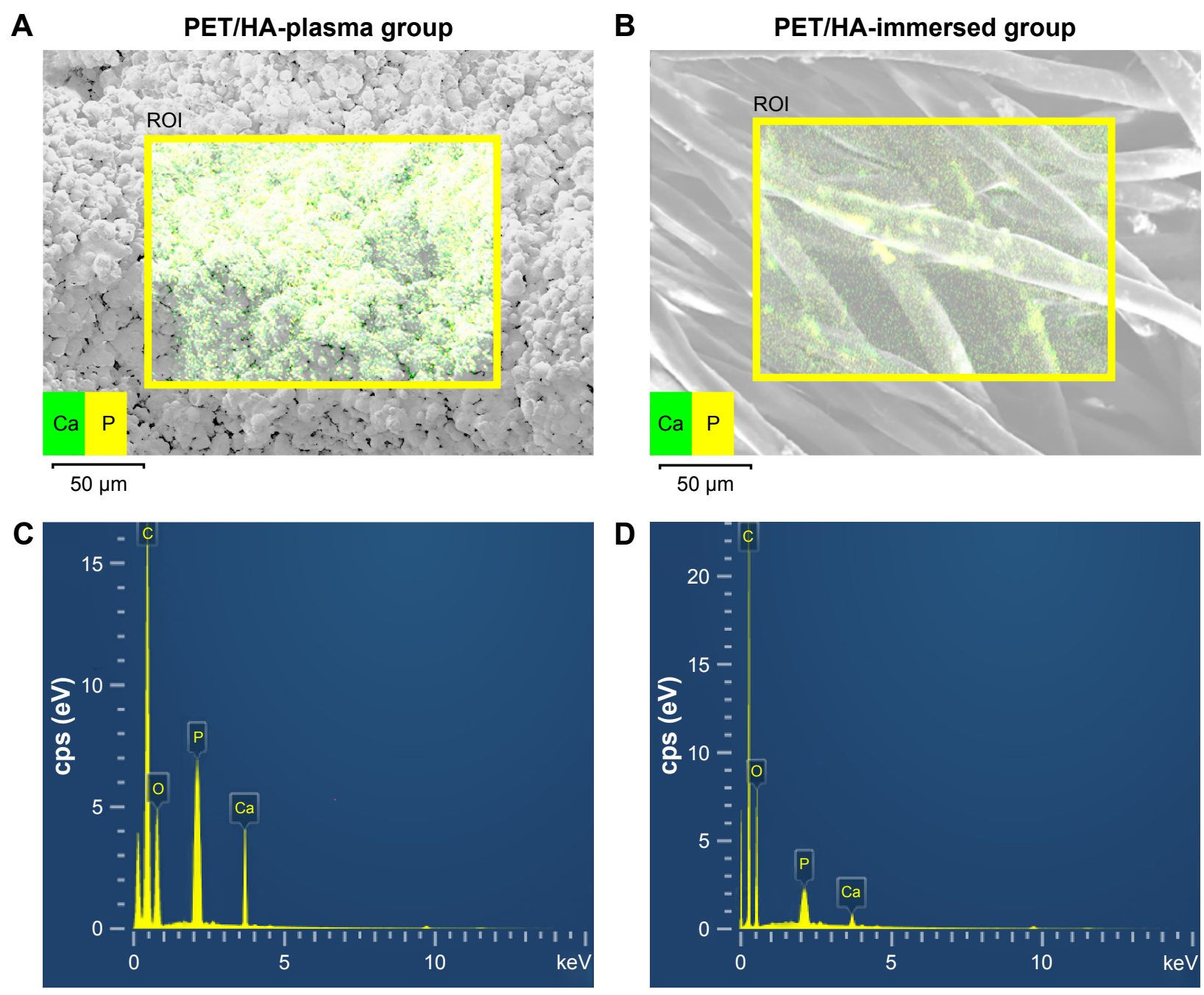

Figure 5 EDS results of HA on PET.

Notes: Elemental mapping of calcium and phosphate on the surface of (A) PET/HA plasma and (B) PET/HA immersed. Energy-dispersive spectrometry in the (C) PET/HAplasma and (D) PET/HA-immersed groups.

Abbreviations: cps, count per second; EDS, energy-dispersive spectrometer; HA, hydroxyapatite; PET, polyethylene terephthalate; ROI, region of interest.

8 weeks showed no significant difference between the PET/ HA-plasma, PET/HA-immersed, and PET control groups. However, the area of femoral tunnel at 12 weeks was $4.79 \pm 0.53 \mathrm{~mm}^{2}$ in the PET/HA-plasma group, which was smaller compared to $5.96 \pm 0.58 \mathrm{~mm}^{2}$ in the PET control group $(p<0.05)$. These results suggested less bone tunnel resorption effect in the PET/HA-plasma group at the femoral site.

As shown in Figure 2D, the area of tibial tunnel at 8 weeks was $4.79 \pm 0.43 \mathrm{~mm}^{2}$ in the PET/HA-plasma group and $5.81 \pm 0.20 \mathrm{~mm}^{2}$ in the PET control group $(p<0.05)$. Moreover, the area of tibial tunnel at 12 weeks was $4.91 \pm 0.33 \mathrm{~mm}^{2}$ in the PET/HA-plasma group and $6.08 \pm 0.19 \mathrm{~mm}^{2}$ in the PET control group $(p<0.05)$. These results indicated that the PET/HA-plasma modification decreased the bone tunnel resorption effect at 8 and 12 weeks.

\section{Histology analysis}

As shown in Figure 8, the transactional sections of bone tunnels were acquired at 4,8 , and 12 weeks postoperatively, and were stained by H\&E and Masson staining. The graftbone healing process was further evaluated by the modified graft-to-bone histologic score, and the result is shown in Figure 9. As shown in Figure 9A, the total score at 8 and 12 weeks postoperatively was significantly higher in the PET/ HA-plasma group compared to that in the PET/HA-immersed $(p<0.05)$ and PET control groups $(p<0.05)$. Specifically, Figure 9B shows that the interface (IF) width score at 8 and 12 weeks is higher in the PET/HA-plasma group compared to that in the PET control group, which indicates an increased IF maturity in the PET/HA-plasma group. In addition, Figure 9C shows that the tissue/total area score at 8 weeks is significantly elevated in the PET/HA-plasma group 
A

B
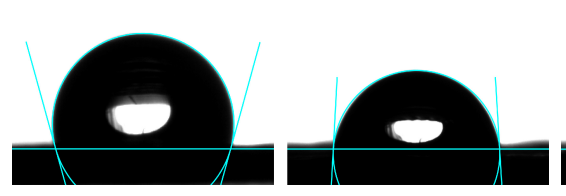

\section{D}

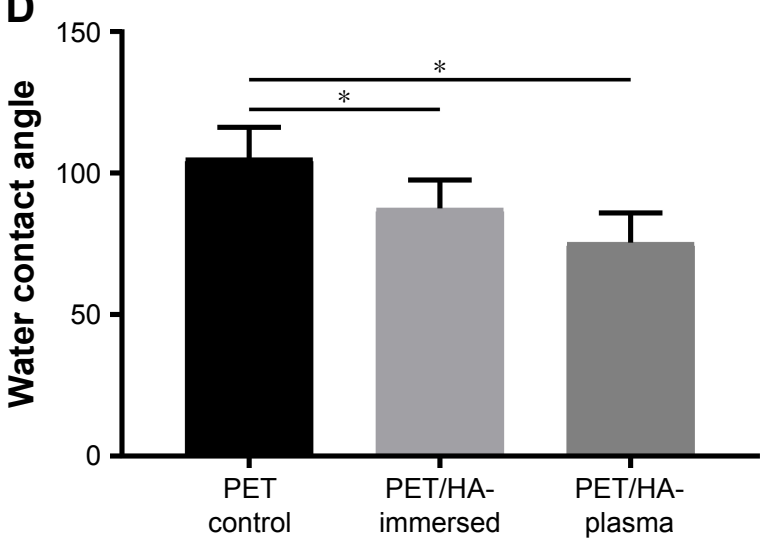

Figure 6 Water contact angle.

Notes: Water contact angle in the (A) PET control, (B) PET/HA-immersed, and (C) PET/HA-plasma groups. (D) Average water contact angle in the PET control, PET/HA-immersed, and PET/HA-plasma groups. $* p<0.05$.

Abbreviations: PET, polyethylene terephthalate; HA, hydroxyapatite.

compared to that in the PET control group $(p<0.05)$, which suggests that tissue ingrowth was significantly increased in the PET/HA-plasma group at 8 weeks. Figure 9D depicts that the cellularity score between groups showed no significant difference between groups at 4, 8, and 12 weeks postoperatively. Figure 9E shows that the rounding of nuclei score at 8 and 12 weeks was higher in the PET/HA-plasma group compared to that in the PET control group, which indicated more formation of fibroblasts in the PET/HA-plasma group. Moreover, Figure 9F shows that the inflammation score at 8 weeks was also higher in the PET/HA-plasma group compared to that in the PET control group, which suggests milder inflammatory infiltration in the PET/HA-plasma group at 8 weeks.

\section{Biomechanical tests}

All the samples in the biomechanical tests were pulled out from tibial tunnel, and no graft rupture was observed in any group. As shown in Figure 3B, the maximum load to failure at 8 weeks was $70.67 \pm 5.48 \mathrm{~N}$ in the PET/HA-plasma group and $65.07 \pm 3.75 \mathrm{~N}$ in the PET/HA-immersed group, which was significantly higher than $49.90 \pm 4.65 \mathrm{~N}$ in the PET control group $(p<0.05)$. In addition, the maximum load to failure at 12 weeks was $78.03 \pm 6.60 \mathrm{~N}$ in the PET/HA-plasma group and $72.30 \pm 3.80 \mathrm{~N}$ in the PET/HA-immersed group, which was significantly higher than $52.60 \pm 5.80 \mathrm{~N}$ in the PET control group $(p<0.05)$.

As shown in Figure $3 \mathrm{C}$, stiffness at 4 weeks was 23.44 $\pm 2.40 \mathrm{~N} / \mathrm{mm}$ in the PET/HA-plasma group and $21.13 \pm 2.91 \mathrm{~N} / \mathrm{mm}$ in the PET/HA-immersed group, which was significantly higher than $15.48 \pm 1.86 \mathrm{~N} / \mathrm{mm}$ in the PET control group $(p<0.05)$. Stiffness at 8 weeks was $26.40 \pm 1.84 \mathrm{~N} / \mathrm{mm}$ in the PET/HA-plasma group and 26.90 $\pm 2.81 \mathrm{~N} / \mathrm{mm}$ in the PET/HA-immersed group, which was significantly higher than $18.90 \pm 1.92 \mathrm{~N} / \mathrm{mm}$ in the PET control group $(p<0.05)$. Moreover, stiffness at 12 weeks was $31.17 \pm 2.49 \mathrm{~N} / \mathrm{mm}$ in the PET/HA-plasma group and $29.72 \pm 2.14 \mathrm{~N} / \mathrm{mm}$ in the PET/HA-immersed group, which was significantly higher than $20.18 \pm 2.04 \mathrm{~N} / \mathrm{mm}$ in the PET control group $(p<0.05)$. These results suggested that the biomechanical performance was improved in the PET/HAplasma group.

\section{Discussion}

LARS ligament made of PET has been recognized as a primal option for ACL reconstruction in clinical practice. ${ }^{3}$ However, PET material was poor in osseointegration, which has limited its clinical applications. Specifically, bone tunnel resorption, synovitis, and graft failure were observed in longterm follow-up, ${ }^{5}$ and the bioinertness of artificial ligament was recognized as a risk factor. The quality of graft-bone integration depends on the implant, surface topography, and biological activity, ${ }^{28}$ and the surface modification of the PET ligament is commonly used to improve its surface topography and biological activity, thus improving its osteoconductivity. ${ }^{29}$ In previous studies, chitosan, ${ }^{30}$ silk fibroin, ${ }^{31}$ graphene oxide, ${ }^{32}$ and material based on calcium phosphate ${ }^{25,33}$ were studied as coating materials. However, this technique was not sufficient to generate a stable coating with a high efficiency. ${ }^{34}$ Bolbasov et $\mathrm{al}^{35}$ reported composite coatings based on a copolymer of vinylidene fluoride with tetrafluoroethylene (VDF-TeFE) and HA for flexible intramedullary nails (FIN), and the results demonstrated improved strength of bonding and osteoinductivity. In this study, PET ligament surface modified with HA by the plasma spraying technique was investigated for its biological and biomechanical performance in vitro and in vivo.

Characteristic tests in this study showed that the surface of PET/HA-plasma sheets was rough, and an increased number of nanoparticles were observed in the PET/HAplasma group. Moreover, the diameter of nanoparticles had a narrow distribution width. These results demonstrated that plasma spraying is an effective technique for HA 


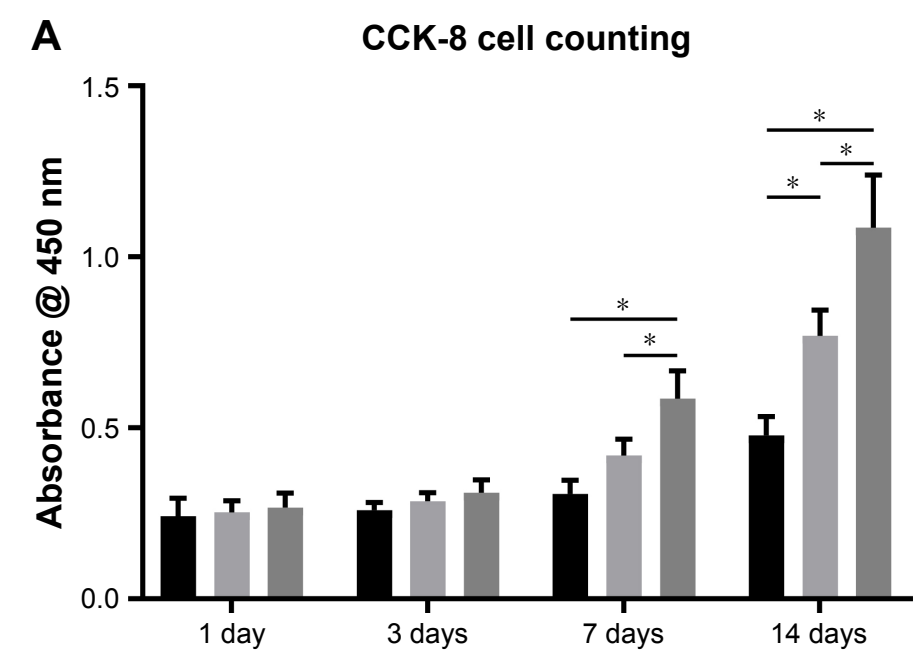

\section{B}

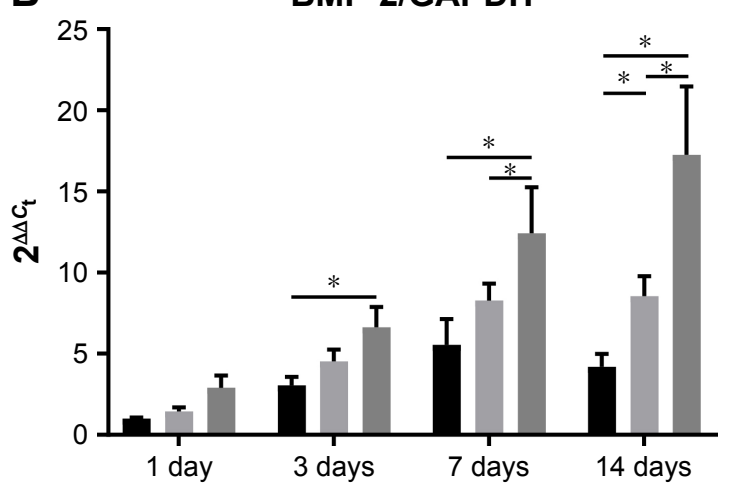

D

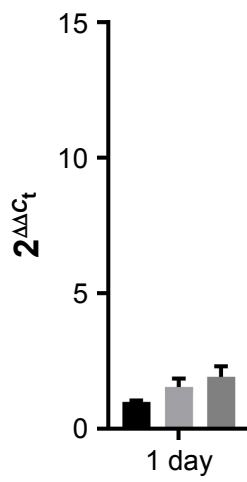

eNOS/GAPDH

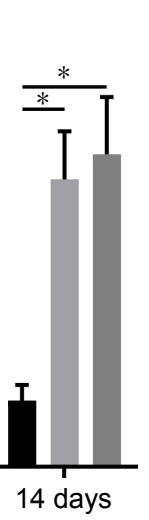

C

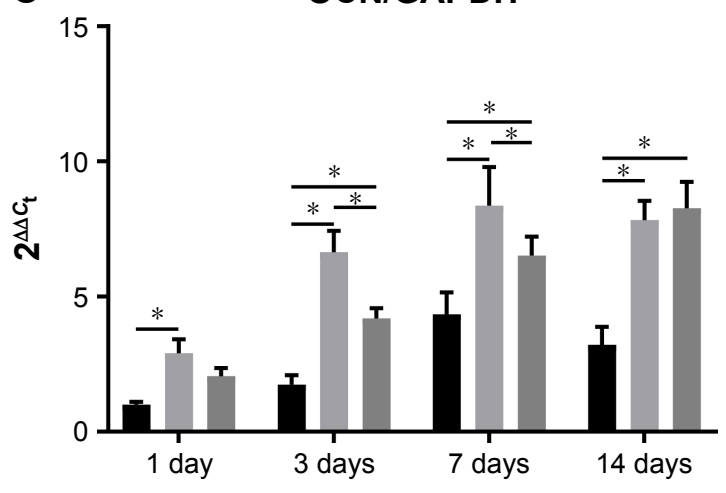

E VEGF/GAPDH

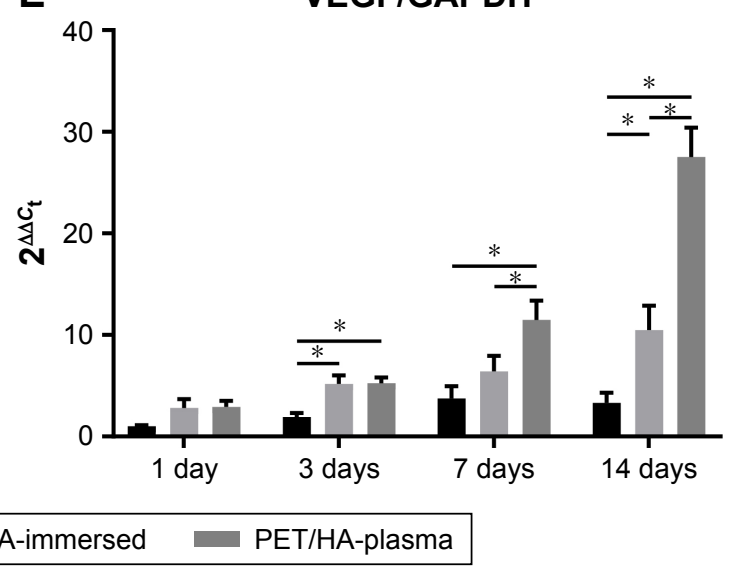

Figure 7 Proliferation and bone formation gene expression level of BMSCs on the grafts.

Notes: (A) Cell proliferation of the BMSCs determined by CCK-8 at I, 3, 7, and I4 days. Expression level of mRNA related to the bone formation process, including (B) BMP-2, (C) OCN, (D) eNOS, and (E) VEGF. ${ }^{*} p<0.05$.

Abbreviations: BMSC, bone marrow stromal cell; CCK-8, cell counting kit 8 .

modification with topological uniformity. Additionally, water contact angle was decreased in the PET/HA-plasma group, which suggested that the hydrophobicity in the PET/ HA-plasma group was decreased. The plasma spraying technique has been investigated in surface modification of medical implants..$^{36-39}$ In this technique, a plasma beam is applied to aim powdered HA at the implant surface, which solidifies on the surface. ${ }^{40}$ This method has been found to induce nucleation and increase the growth of apatite on the implant surface. ${ }^{41}$ Specifically, Wang et a ${ }^{37}$ reported that the HA coating texture in plasma surface modification was a mixture of columnar and random-oriented crystals, which has 
A

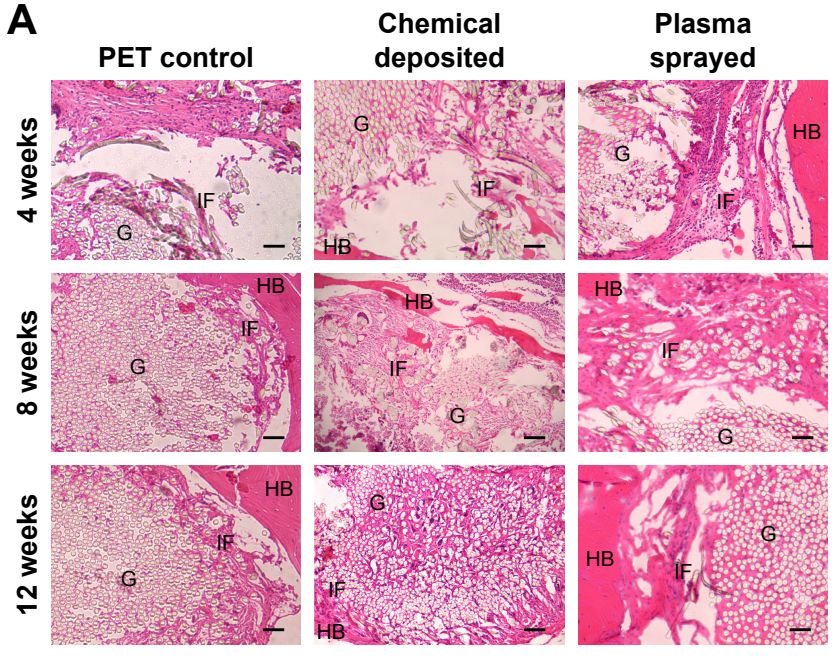

B

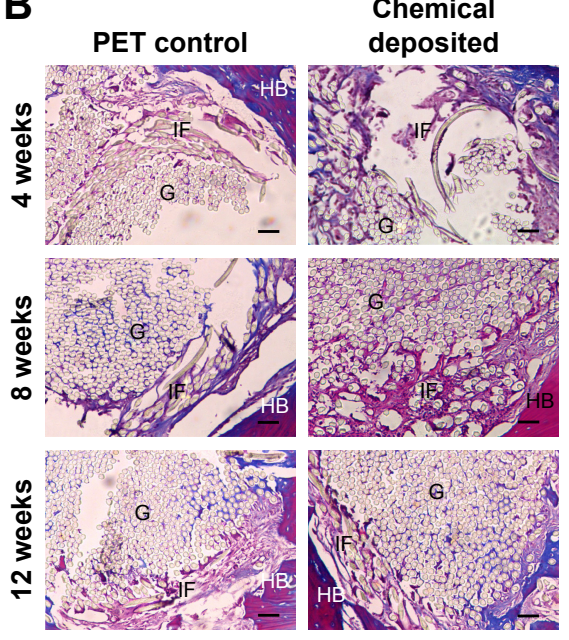

Plasma sprayed

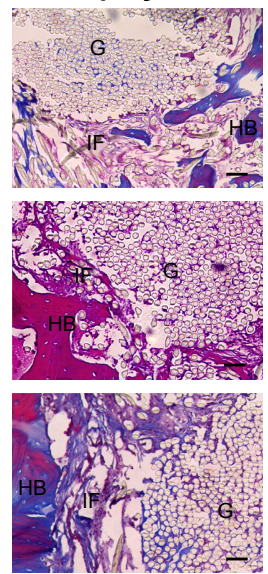

Figure 8 Representative images of bone-graft IF at 4, 8, and 12 weeks post surgery.

Notes: (A) H\&E staining results for the graft-bone IF of the PET control, chemical-deposited, and plasma-sprayed groups. (B) Masson trichrome staining showing fibrocartilage formation between the bone and grafts. Bar $=100 \mu \mathrm{m}$.

Abbreviations: IF, interface; H\&E, hematoxylin-eosin; PET, polyethylene terephthalate; G, grafts; HB, host bone.

a better potential in cell proliferation. The result of our work is consistent with those studies that proved that the coating can decrease hydrophobicity. However, the plasma spraying technique used in metal surface modification has a high working temperature, ${ }^{37}$ which is higher than the phase changing point of PET. The temperature threshold has made the application of this technology in the field of polymer surface modification limited. In our study, the spraying distance of plasma spraying was increased, and the spraying time was shortened when processing PET sheet. In this way, we succeeded in spraying the HA nanoparticles onto the surface of the PET material.

The in vitro biocompatibility work of this study demonstrated that the osteoconductivity was improved in the PET/ HA-plasma group. CCK-8 counting result indicated that the proliferation of BMSCs was increased in the PET/HA-plasma group. Moreover, the mRNA expression of BMP-2, OCN, eNOS, and VEGF was upregulated in the PET/HA-plasma group, which suggested that these genes contributed to promoting the BMSC proliferation in the PET/HA-plasma group. Notably, the level of BMP-2 and VEGF is significantly upregulated in the PET/HA-plasma group compared to that in the PET/HA-immersed group, which suggested that the topological morphology of HA-plasma coating can upregulate the expression of BMP-2 and VEGF. BMP-2 as a kind of cytokine can induce ectopic osteogenesis; it can induce BMSCs to differentiate from osteoblasts with the highest efficiency in the BMP family. ${ }^{42}$ Jiang et al ${ }^{43}$ reported that the expression of BMP and VEGF is closely related, which is consistent with our RT-PCR findings. VEGF is a major contributor to osteogenesis, which has the most direct and exclusive effect among all kinds of growth factors on the endothelial cells of the vessel. It enhances absorption of the cartilage and participates in initiating osteogenesis within the cartilage by promoting angiogenesis, thus acting as an important regulator during both early and late stages of endochondral ossification. ${ }^{44} \mathrm{OCN}$, also known as bone Gla protein, is a noncollagenous matrix protein found in the bone and dentin, has been postulated to play roles in bone formation and remodeling. ${ }^{45}$ Boskey et $\mathrm{al}^{46}$ investigated the bone in OCN-deficient mice by Fourier transform infrared microspectroscopic analysis and proved that OCN is required to stimulate bone mineral maturation. Kim et a ${ }^{47}$ also reported that fluoridation of HA increased significantly the alkaline phosphatase activity and OCN production. eNOS has been found to be involved in fracture healing. Meesters et $\mathrm{al}^{48}$ reported that the absence of nitric oxide synthases results in a disturbed arginine-nitric oxide (NO) metabolism and inadequate fracture healing with the transition of delayed union into a nonunion in mice after a femur osteotomy. Furuno et a $1^{49}$ suggested the crucial vasculoprotective role of the whole endogenous nitric oxide synthase (NOS) system and that the NOS system in bone marrow-derived cells may be involved in this vasculoprotective mechanism. These works are consistent with our results, suggesting that BMP-2, OCN, eNOS, and VEGF participated in the bone healing process in the PET/HA-plasma group.

Micro-CT results showed that there was decreased bone resorption and increased bone ingrowth at the graft-bone IF of the PET/HA-plasma group bone tunnel compared with that 

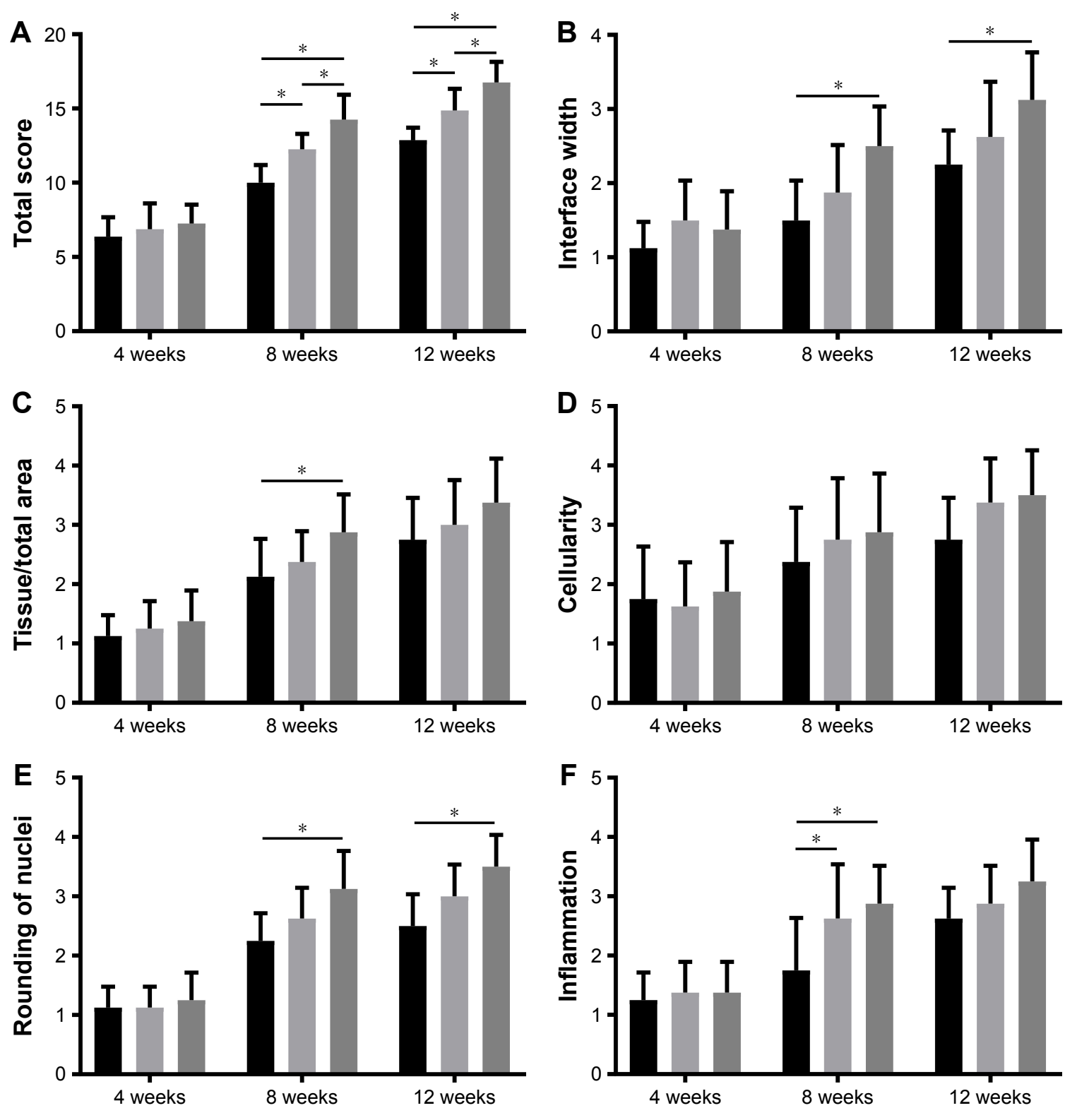

PET control PET/HA-immersed PET/HA-plasma

Figure 9 Statistical analysis of the modified graft-to-bone score.

Notes: (A) Total score, (B) IF width score, (C) tissue/total area score, (D) cellularity score, (E) rounding of nuclei score, and $(\mathbf{F})$ inflammation score. $* p<0.05$. Abbreviations: IF, interface; PET, polyethylene terephthalate; HA, hydroxyapatite.

of the control group after surgery. Bone tunnel resorption is a common complication after ACL reconstruction with artificial ligament. ${ }^{50}$ According to Agarwal and García, ${ }^{51}$ a synthetic device for ACL reconstruction is required to undertake constantly tensile load, and it can fail due to implant motion, inflammation, bone resorption, and osteolysis. The decrease in bone tunnel resorption indicated improved host-to-graft integrating, which is consistent with the results of our biomechanical tests. In this study, all samples in the biomechanical test were pulled out from tibial tunnel, revealing that in this model, shearing force between the host and the graft is the determinative factor for mechanical strength. Less cancellous bone distribution at the tibial site in rabbits resulted in the tibial pullout. The biomechanical test of stiffness and ultimate load to failure was higher in the PET/HA-plasma and PET/HA-immersed groups compared to that in the PET control group, which provided positive evidence for better host-to-graft integrity in PET coated with HA.

The modified graft-to-bone histological score ${ }^{26,27}$ was introduced in this study to quantify the histological results. 
The significant results in the total score between groups at 8 and 12 weeks postoperatively indicated that plasma spraying with HA on PET can enhance connection between host tissue and grafts. Specifically, the IF width score and rounding of nuclei score were higher in the PET/HA-plasma group compared to those in the PET control group. These results suggested that the IF maturity and the formation of spindle-shaped cells were of significant difference between the PET/HA-plasma and PET control groups. According to Shen et al, ${ }^{52}$ direct insertion and indirect insertion are the two types of connection at native IF between ACL ligament and bone. Direct insertion is composed of tendon, unmineralized fibrocartilage, mineralized fibrocartilage, and bone, while indirect insertion anchors the ligament to periosteum by Sharpey's fibers. ${ }^{11} \mathrm{Li}$ et $\mathrm{al}^{29}$ and Ai et al ${ }^{11}$ have reported IF between the graft and the host bone matured with narrowed width, fibrocartilage formation, and Sharpey's fiber formation at 12 weeks after ACL reconstruction, which is in consistent with our work.

\section{Conclusion}

In this study, the plasma spraying technique was applied to modify PET with HA, which is novel for coating on fenestral fabric and can provide insights into ligament modification. The coating method has been proved to have high efficiency and can produce topologically uniform surface. Water contact angle test demonstrated improved hydrophilicity by HA plasma spraying. In vitro study demonstrated increased cytoviability and increased mRNA expression of BMP-2, VEGF, OCN, and eNOS. These results suggested that the plasma HA modification had a promotive effect on mRNA expression of these genes. In vivo test demonstrated that the plasma spraying technique limited bone tunnel resorption and improved biomechanical strength of the bone-graft complex. Histological scoring results indicated that HA plasma spraying can promote osseointegration. All of these results proved that the method is of great potential for ACL reconstruction application.

\section{Acknowledgments}

This work was supported by National Key R\&D Program of China (2016YFC1100300, 2017YFC0840100 and 2017YFC0840106), National Natural Science Foundation of China (No. 81572108 and No. 81772339), The Key Clinical Medicine Center of Shanghai (2017ZZ01006), Sanming Project of Medicine in Shenzhen (SZSM201612078) and Shanghai Rising-star project (18QB1400500).

\section{Author contributions}

All authors contributed toward data analysis, drafting and revising the paper and agree to be accountable for all aspects of the work.

\section{Disclosure}

The authors report no conflicts of interest in this work.

\section{References}

1. Mall NA, Chalmers PN, Moric M, et al. Incidence and trends of anterior cruciate ligament reconstruction in the United States. Am J Sports Med. 2014;42(10):2363-2370.

2. Batty LM, Norsworthy CJ, Lash NJ, Wasiak J, Richmond AK, Feller JA. Synthetic devices for reconstructive surgery of the cruciate ligaments: a systematic review. Arthroscopy. 2015;31(5):957-968.

3. Newman SD, Atkinson HD, Willis-Owen CA. Anterior cruciate ligament reconstruction with the ligament augmentation and reconstruction system: a systematic review. Int Orthop. 2013;37(2):321-326.

4. Chen J, Gu A, Jiang H, Zhang W, Yu X. A comparison of acute and chronic anterior cruciate ligament reconstruction using LARS artificial ligaments: a randomized prospective study with a 5-year follow-up. Arch Orthop Trauma Surg. 2015;135(1):95-102.

5. Li H, Yao Z, Jiang J, et al. Biologic failure of a ligament advanced reinforcement system artificial ligament in anterior cruciate ligament reconstruction: a report of serious knee synovitis. Arthroscopy. 2012; 28(4):583-586.

6. Cobbs W, Burton R. Crystallization of polyethylene terephthalate. J Polym Sci A Polym Chem. 1953;10(3):275-290.

7. Parvinzadeh M, Moradian S, Rashidi A, Yazdanshenas M-E. Surface characterization of polyethylene terephthalate/silica nanocomposites. Appl Surf Sci. 2010;256(9):2792-2802.

8. Li H, Chen S, Wu Y, et al. Enhancement of the osseointegration of a polyethylene terephthalate artificial ligament graft in a bone tunnel using 58S bioglass. Int Orthop. 2012;36(1):191-197.

9. Oh SH, Kang SG, Kim ES, Cho SH, Lee JH. Fabrication and characterization of hydrophilic poly (lactic-co-glycolic acid)/poly (vinyl alcohol) blend cell scaffolds by melt-molding particulate-leaching method. Biomaterials. 2003;24(22):4011-4021.

10. Cho S, Li H, Chen C, Jiang J, Tao H, Chen S. Cationised gelatin and hyaluronic acid coating enhances polyethylene terephthalate artificial ligament graft osseointegration in porcine bone tunnels. Int Orthop. 2013;37(3):507-513.

11. Ai C, Sheng D, Chen J, et al. Surface modification of vascular endothelial growth factor-loaded silk fibroin to improve biological performance of ultra-high-molecular-weight polyethylene via promoting angiogenesis. Int J Nanomedicine. 2017;12:7737-7750.

12. Chen C, Li H, Guo C, Chen S. Preparation and in vitro evaluation of a biomimetic nanoscale calcium phosphate coating on a polyethylene terephthalate artificial ligament. Exp Ther Med. 2016;12(1):302-306.

13. Crouzier T, Sailhan F, Becquart P, Guillot R, Logeart-Avramoglou D, Picart C. The performance of BMP-2 loaded TCP/HAP porous ceramics with a polyelectrolyte multilayer film coating. Biomaterials. 2011; 32(30):7543-7554.

14. Liu H, Peng H, Wu Y, et al. The promotion of bone regeneration by nanofibrous hydroxyapatite/chitosan scaffolds by effects on integrinBMP/Smad signaling pathway in BMSCs. Biomaterials. 2013;34(18): 4404-4417.

15. Xiong H, Du S, Ni J, Zhou J, Yao J. Mitochondria and nuclei dualtargeted heterogeneous hydroxyapatite nanoparticles for enhancing therapeutic efficacy of doxorubicin. Biomaterials. 2016;94:70-83.

16. Liu X, Cao J, Li H, et al. Mussel-inspired polydopamine: a biocompatible and ultrastable coating for nanoparticles in vivo. ACS Nano. 2013; 7(10):9384-9395. 
17. Strąkowska P, Beutner R, Gnyba M, Zielinski A, Scharnweber D. Electrochemically assisted deposition of hydroxyapatite on Ti6Al4V substrates covered by CVD diamond films - coating characterization and first cell biological results. Mater Sci Eng C Mater Biol Appl. 2016; 59:624-635.

18. Koirala MB, Nguyen TD, Pitchaimani A, Choi SO, Aryal S. Synthesis and characterization of biomimetic hydroxyapatite nanoconstruct using chemical gradient across lipid bilayer. ACS Appl Mater Interfaces. 2015; 7(49):27382-27390.

19. Bogya ES, Károly Z, Barabás R. Atmospheric plasma sprayed silicahydroxyapatite coatings on magnesium alloy substrates. Ceram Int. 2015;41(4):6005-6012.

20. Nimkerdphol AR, Otsuka Y, Mutoh Y. Effect of dissolution/precipitation on the residual stress redistribution of plasma-sprayed hydroxyapatite coating on titanium substrate in simulated body fluid (SBF). $J$ Mech Behav Biomed Mater. 2014;36:98-108.

21. Vogel D, Dempwolf H, Baumann A, Bader R. Characterization of thick titanium plasma spray coatings on PEEK materials used for medical implants and the influence on the mechanical properties. JMech Behav Biomed Mater. 2018;77:600-608.

22. Ohtsu N, Hiromoto S, Yamane M, et al. Chemical and crystallographic characterizations of hydroxyapatite- and octacalcium phosphatecoatings on magnesium synthesized by chemical solution deposition using XPS and XRD. Surf Coat Technol. 2013;218:114-118.

23. Zuidema JM, Kumeria T, Kim D, et al. Oriented nanofibrous polymer scaffolds containing protein-loaded porous silicon generated by spray nebulization. Adv Mater. 2018;30(12):e1706785.

24. Tsuda H, Wada T, Yamashita T, Hamada H. Enhanced osteoinduction by mesenchymal stem cells transfected with a fiber-mutant adenoviral BMP2 gene. J Gene Med. 2005;7(10):1322-1334.

25. Jiang J, Wan F, Yang J, et al. Enhancement of osseointegration of polyethylene terephthalate artificial ligament by coating of silk fibroin and depositing of hydroxyapatite. Int J Nanomedicine. 2014;9:4569-4580.

26. Suh D-S, Lee J-K, Yoo J-C, et al. Atelocollagen enhances the healing of rotator cuff tendon in rabbit model. Am J Sports Med. 2017;45(9): 2019-2027.

27. Chen J, Yu Q, Wu B, et al. Autologous tenocyte therapy for experimental Achilles tendinopathy in a rabbit model. Tissue Eng Part A. 2011; 17(15-16):2037-2048.

28. Mao L, Liu J, Zhao J, et al. Effect of micro-nano-hybrid structured hydroxyapatite bioceramics on osteogenic and cementogenic differentiation of human periodontal ligament stem cell via Wnt signaling pathway. Int J Nanomedicine. 2015;10:7031-7044.

29. Li H, Chen S, Chen J, et al. Mussel-inspired artificial grafts for functional ligament reconstruction. ACS Appl Mater Interfaces. 2015;7(27): 14708-14719.

30. Shao HJ, Sang CC, Yu-Tsang L, et al. The phenotypic responses of human anterior cruciate ligament cells cultured on poly( $\varepsilon$-caprolactone) and chitosan. J Biomed Mater Res A. 2010;93(4):1297-1305.

31. Farè $S$, Torricelli $P$, Giavaresi G, et al. In vitro study on silk fibroin textile structure for anterior cruciate ligament regeneration. Mater Sci Eng C Mater Biol Appl. 2013;33(7):3601-3608.

32. Ardjomandi N, Henrich A, Huth J, et al. Coating of ss-tricalcium phosphate scaffolds-a comparison between graphene oxide and polylactic-co-glycolic acid. Biomed Mater. 2015;10(4):045018.

33. Li H, Chen C, Zhang S, et al. The use of layer by layer self-assembled coatings of hyaluronic acid and cationized gelatin to improve the biocompatibility of poly (ethylene terephthalate) artificial ligaments for reconstruction of the anterior cruciate ligament. Acta Biomater. 2012; 8(11):4007-4019.

34. Ignjatović N, Wu V, Ajduković Z, Mihajilov-Krstev T, Uskoković V, Uskoković D. Chitosan-PLGA polymer blends as coatings for hydroxyapatite nanoparticles and their effect on antimicrobial properties, osteoconductivity and regeneration of osseous tissues. Mater Sci Eng C. 2016;60:357-364
35. Bolbasov EN, Popkov AV, Popkov DA, et al. Osteoinductive composite coatings for flexible intramedullary nails. Mater Sci Eng C Mater Biol Appl. 2017;75:207-220.

36. Walsh WR, Bertollo N, Christou C, Schaffner D, Mobbs RJ. Plasmasprayed titanium coating to polyetheretherketone improves the boneimplant interface. Spine J. 2015;15(5):1041-1049.

37. Wang Y, Liu X, Fan T, Tan Z, Zhou Z, He D. In vitro evaluation of hydroxyapatite coatings with (002) crystallographic texture deposited by micro-plasma spraying. Mater Sci Eng C Mater Biol Appl. 2017; 75:596-601.

38. Huang Y, He J, Gan L, et al. Osteoconductivity and osteoinductivity of porous hydroxyapatite coatings deposited by liquid precursor plasma spraying: in vivo biological response study. Biomed Mater. 2014; 9(6):065007.

39. Kulkarni M, Mazare A, Schmuki P, Iglič A. Biomaterial surface modification of titanium and titanium alloys for medical applications. Nanomedicine. 2014;111:111-136.

40. Duan K, Wang R. Surface modifications of bone implants through wet chemistry. J Mater Chem. 2006;16(24):2309-2321.

41. Jemat A, Ghazali MJ, Razali M, Otsuka Y. Surface modifications and their effects on titanium dental implants. Biomed Res Int. 2015, 11 pages.

42. Geuze RE, Theyse LF, Kempen DH, et al. A differential effect of bone morphogenetic protein-2 and vascular endothelial growth factor release timing on osteogenesis at ectopic and orthotopic sites in a large-animal model. Tissue Eng Part A. 2012;18(19-20):2052-2062.

43. Jiang J, Sheng D, Chai F, et al. The study on vascularisation and osteogenesis of BMP/VEGF co-modified tissue engineering bone in vivo. RSC Adv. 2016;6(48):41800-41808.

44. Qian J, Suo A, Jin X, Xu W, Xu M. Preparation and in vitro characterization of biomorphic silk fibroin scaffolds for bone tissue engineering. J Biomed Mater Res A. 2014;102(9):2961-2971.

45. Ulrich MM, Perizonius WR, Spoor CF, Sandberg P, Vermeer C. Extraction of osteocalcin from fossil bones and teeth. Biochem Biophys Res Commun. 1987;149(2):712-719.

46. Boskey AL, Gadaleta S, Gundberg C, Doty SB, Ducy P, Karsenty G. Fourier transform infrared microspectroscopic analysis of bones of osteocalcin-deficient mice provides insight into the function of osteocalcin. Bone. 1998;23(3):187-196.

47. Kim HW, Lee EJ, Kim HE, Salih V, Knowles JC. Effect of fluoridation of hydroxyapatite in hydroxyapatite-polycaprolactone composites on osteoblast activity. Biomaterials. 2005;26(21):4395-4404.

48. Meesters DM, Neubert S, Wijnands KAP, et al. Deficiency of inducible and endothelial nitric oxide synthase results in diminished bone formation and delayed union and nonunion development. Bone. 2016;83:111-118.

49. Furuno Y, Morishita T, Toyohira Y, et al. Crucial vasculoprotective role of the whole nitric oxide synthase system in vascular lesion formation in mice: involvement of bone marrow-derived cells. Nitric Oxide. 2011; 25(3):350-359

50. Gao K, Chen S, Wang L, et al. Anterior cruciate ligament reconstruction with LARS artificial ligament: a multicenter study with 3- to 5-year follow-up. Arthroscopy. 2010;26(4):515-523.

51. Agarwal R, García AJ. Biomaterial strategies for engineering implants for enhanced osseointegration and bone repair. Adv Drug Deliv Rev. 2015;94:53-62.

52. Shen H, Qiao G, Cao H, Jiang Y. An histological study of the influence of osteoinductive calcium phosphate ceramics on tendon healing pattern in a bone tunnel with suspensory fixation. Int Orthop. 2010; 34(6):917-924 
International Journal of Nanomedicine

Dovepress

\section{Publish your work in this journal}

The International Journal of Nanomedicine is an international, peerreviewed journal focusing on the application of nanotechnology in diagnostics, therapeutics, and drug delivery systems throughou the biomedical field. This journal is indexed on PubMed Central, MedLine, CAS, SciSearch ${ }^{\circledR}$, Current Contents ${ }^{\circledR} /$ Clinical Medicine,
Journal Citation Reports/Science Edition, EMBase, Scopus and the Elsevier Bibliographic databases. The manuscript management system is completely online and includes a very quick and fair peer-review system, which is all easy to use. Visit http://www.dovepress.com/ testimonials.php to read real quotes from published authors.

Submit your manuscript here: http://www.dovepress.com/international-journal-of-nanomedicine-journal 